\section{(2)} OPEN ACCESS

\title{
Household economic burden of childhood severe pneumonia in Bangladesh: a cost-of-illness study
}

\author{
Marufa Sultana (D) , ${ }^{1,2}$ Nur H Alam, ${ }^{1,3}$ Nausad Ali, ${ }^{1}$ A S G Faruque, ${ }^{1}$ George J Fuchs, ${ }^{4}$ \\ Niklaus Gyr, ${ }^{5}$ Md Jobayer Chisti, ${ }^{1}$ Tahmeed Ahmed (D) ,' Lisa Gold ${ }^{2}$
}

\begin{abstract}
- Additional supplemental material is published online only. To view, please visit the journal online (http://dx.doi. org/10.1136/archdischild2020-320834)
\end{abstract}

${ }^{1}$ Nutrition and Clinical Services Division, icddr,b, Dhaka, Bangladesh

'Deakin Health Economics, School of Health and Social Development, Deakin University, Geelong, Victoria, Australia ${ }^{3}$ Clinical Sciences Division (CSD), Centre for Nutrition and Food Security (CNFS), Dhaka, Bangladesh

${ }^{4}$ Department of Paediatrics, University of Kentucky College of Medicine and Department of Epidemiology, College of Public Health, University of Kentucky, Lexington, Kentucky, USA ${ }^{5}$ Department of Internal Medicine, University of Basel, Basel, Switzerland

\section{Correspondence to}

Dr Marufa Sultana, Nutrition and Clinical Services Division, icddr,b, Dhaka 1212

Bangladesh; marufa@icddrb.org Published Online First 27 April 2021

\section{Check for updates}

(C) Author(s) (or their employer(s)) 2021. Re-use permitted under CC BY-NC. No commercial re-use. See rights and permissions. Published by BMJ.

To cite: Sultana M, Alam NH Ali N, et al. Arch Dis Child 2021;106:539-546.

\begin{abstract}
Objective To estimate household cost of illness (COI)

for children with severe pneumonia in Bangladesh.

Design An incidence-based COI study was performed for one episode of childhood severe pneumonia from a household perspective. Face-to-face interviews collected data on socioeconomic, resource use and cost from caregivers. A micro-costing bottom-up approach was applied to calculate medical, non-medical and time costs. Multiple regression analysis was applied to explore the factors associated with COI. Sensitivity analysis explored the robustness of cost parameters.
\end{abstract}

Setting Four urban and rural study sites from two districts in Bangladesh.

Patients Children aged 2-59 months with severe pneumonia.

Results 1472 children with severe pneumonia were enrolled between November 2015 and March 2019. The mean age of children was 12 months (SD \pm 10.2 ) and $64 \%$ were male. The mean household cost per episode was US\$147 (95\% Cl 141.1 to 152.7$)$. Indirect costs were the main cost drivers $(65 \%$, US\$96). Household costs for the poorest income quintile were lower in absolute terms, but formed a higher proportion of monthly income. COI was significantly higher if treatment was received from urban health facilities compared with rural health facilities (difference US $\$ 84.9,95 \% \mathrm{Cl}$ 73.3 to 96.3 ). Child age, household income, healthcare facility and hospital length of stay (LoS) were significant predictors of household COI. Costs were most sensitive to hospital LoS and productivity loss.

Conclusions Severe pneumonia in young children is associated with high household economic burden and cost varies significantly across socioeconomic parameters. Management strategies with improved accessibility are needed particularly for the poor to make treatment affordable in order to reduce household economic burden.

\section{BACKGROUND}

Pneumonia is the leading cause of death among under-5 children worldwide, with an estimated 0.8 million deaths in 2017. ${ }^{12}$ Mortality is disproportionately higher in low-income and middleincome countries (LMICs), where 95\%-99\% of pneumonia-specific under-5 deaths occur. ${ }^{3}$ The estimated incidence of clinical pneumonia among under-5 children in LMICs is 0.28 episodes per child-year and is predominant in South Asia and sub-Saharan Africa. ${ }^{45} \mathrm{~A}$ total of $12 \%$ of pneumonia episodes progressed to severe pneumonia, which relies on hospitalisation with supportive treatment

\section{What is already known on this topic?}

Pneumonia is the leading cause of death among under-5 children worldwide.

- Seeking care for pneumonia is poor in resourcepoor countries and involves substantial costs for households, particularly for lower socioeconomic groups.

- Previous studies, largely from small urban and small-scaled samples, estimated the cost of management from US\$42 to US\$5977 per episode of severe pneumonia.

\section{What this study adds?}

- The study estimated the mean household cost (US\$147) with a large sample from rural and urban areas in Bangladesh using a microcosting approach.

- The study identified the common resources used and calculated the indirect costs to unpaid caregivers (US\$95), along with direct medical and non-medical costs.

- The study compared cost burden according to socioeconomic group and facility location, assessed the predictors of cost and determined cost-sensitive parameters.

and careful monitoring. ${ }^{5-8}$ In Bangladesh, pneumonia accounts for $28 \%$ of under-5 mortality and about $40 \%$ of paediatric hospital admissions, ${ }^{9} 10$ while only $42 \%$ of parents report seeking care from trained providers for a child with pneumonia symptoms. ${ }^{11}$

Childhood pneumonia imposes high economic burden on households, healthcare systems and society as a whole. ${ }^{1213}$ The high prevalence among lower socioeconomic groups in Bangladesh is a significant concern because a substantial amount of costs are borne by households when seeking care from any healthcare facility. ${ }^{14-17}$ In a systematic analysis, Zhang et al ${ }^{12}$ reported the costs of pneumonia management, where the cost of inpatient care ranged from US\$42 to US\$5977 (2019 inflationadjusted). Three studies were conducted in Bangladesh but were small-scaled, limited in terms of the scope of costs included and were largely conducted in urban areas. ${ }^{18-20}$ In addition, evidence from the review reveals methodological limitations with lack of detailed information on resource use, particularly from the household's perspective. ${ }^{12}$ 
Detailed cost estimation based on rigorous methodologies is crucial to accurately inform policy to efficiently allocate scarce resources. In this context, the current study intended to estimate the household cost of illness (COI) per episode of childhood severe pneumonia, to assess cost variation across rural and urban groups, and to determine the associated predictors in the context of Bangladesh.

\section{MATERIALS AND METHODS \\ Study setting}

This study was nested in an effectiveness trial that compared daycare management approach (DCA) with usual care for treatment of childhood severe pneumonia. The trial was conducted by the International Centre for Diarrhoeal Disease Research, Bangladesh between November 2015 and March 2019 and covered an urban district (Dhaka) and a rural district (Kishoreganj). In this effectiveness trial, severe pneumonia in children aged 2-59 months was defined following the WHO criteria as 'cough or difficulty in breathing, plus at least one of the following: central cyanosis or oxygen saturation $<90 \%$ on pulse oximetry, severe respiratory distress (e.g., grunting, very severe chest indrawing), signs of pneumonia with a general danger sign: inability to breastfeed or drink, lethargy or unconscious, convulsions'. ${ }^{8}$

\section{Study sites and sample}

A total of 32 public or non-governmental organisation-run clinics (clusters) were randomly selected from the trial sites and allocated equally to either DCA or usual care management. For usual care (control clusters), enrolled children were referred directly to the local hospitals after initial assessment. The referral patterns in the control arm of the trial were unchanged from usual practice, with trial setting having no influence on participant behaviour or referral patterns. All enrolled children in the control clusters $(n=16)$ were included for household COI estimation in the study.

\section{Method of measuring cost}

This study adopted a household perspective to estimate incidence-based COI for one episode of childhood severe pneumonia. Household costs include all illness-related out-of-pocket (OOP) costs and time cost/wage loss of patients and caregivers. The main cost components included direct medical, direct nonmedical and indirect costs.

\section{Identification of resources}

A bottom-up micro-costing approach was applied to collect all relevant economic data related to resource use associated with pneumonia treatment. ${ }^{21}$ This involved identification of all resources used, with the quantity and unit price of each item. Medical care expenses such as physician consultation fees, medicines, diagnostic tests and bed charges were considered as direct medical costs. Non-medical expenses such as transportation, food and lodging were considered as direct non-medical costs ${ }^{21}$ (online supplemental material 1 table S1).

Indirect costs refer to income and/or productivity loss incurred due to illness. ${ }^{22}$ The human capital approach was applied to estimate lost wages/productivity, using self-reported wage rate/ direct income loss for paid workers as per earlier studies and the minimum hourly wage rate for unpaid workers in Bangladesh. ${ }^{17182324}$

\section{Data collection too}

Existing literature and prior experience of the research team were used to design the COI questionnaire. ${ }^{12} 15161823$ Data collection tools (household questionnaire) were piloted in both urban and rural areas to identify questions/variables that needed to be added or excluded and to identify potential barriers (online supplemental material 2). All of the identified challenges were resolved before final data collection. Trained and experienced interviewers collected data in face-to-face interviews with the parent/caregiver. Interviews were conducted on the day of trial enrolment and on the day of hospital discharge. Data on demographics, socioeconomic characteristics, resource use (quantity and expenses), waiting time, caregivers' time, wage and/or productivity loss, and household coping strategies to manage expenses were collected. To reduce recall bias and minimise reporting errors, the interviewee was asked to check items, quantities and prices from purchase receipts or prescriptions. Informed written consent was taken prior to the start of each interview.

\section{Data analysis}

Data were checked to identify potential errors and then verified to conserve data accuracy. Cost data were skewed; therefore, we presented median and IQR along with mean and SD in US dollars, in 2019 price year. Due to skewness, log-linear models were adopted to explore the predictors of household costs. ${ }^{25}$ Household cost was considered as the dependent variable and logged-linear regression models were constructed using demographic and socioeconomic variables. ${ }^{12}$ Variables were added to the regression model that had a correlation coefficient of $>0.15$ with the dependent variable. A multivariate logged linear regression model was used to adjust for potential confounding factors; a low mean value of variance inflation factor confirms that there was no notable multicollinearity in the model.

One-way sensitivity analysis was undertaken to test the robustness of the results. We tested the effect of changes of $\pm 20 \%$ in each cost parameter value for both direct and indirect costs and \pm 1 day in average length of stay (LoS) to identify the most costsensitive parameters. ${ }^{18} 24$ Mean imputation method was used to replace any missing data. ${ }^{26}$ All analyses were undertaken first as complete case and then using mean imputation. Imputed results are presented, although given the low level of missing data (2\%) complete case results were very similar (online supplemental material 3 table S2 and S3). Statistical significance level was considered as $\mathrm{p}$ value less than 0.05 with $95 \%$ CI. All analyses were performed using STATA V.16.1 statistical software.

Written informed consent was taken from the parents/ guardians of the recruited children prior to data collection.

\section{RESULTS}

\section{Background characteristics of the study participants}

Background characteristics of the children are described in table 1 by urban and rural distribution. A total of 1472 children were enrolled, of whom $65 \%$ were male, with a mean age of 12.2 ( $S D \pm 10.2$ ) months. Age and gender distributions were similar for the urban and rural groups. Overall, age was skewed, with $65 \%$ of children aged up to 1 year. The sample revealed skewness towards the wealthier quintiles, particularly in urban areas (table 1). The average monthly household income was US\$277 (SD \pm 275 ), with higher income for urban residents. The average LoS in hospital was 5.0 days. 
Table 1 Background characteristics of under-5 children with severe pneumonia in Bangladesh ( $\mathrm{N}=1472)$

\begin{tabular}{|c|c|c|c|}
\hline Variables & Overall $(\mathrm{N}=1472)$ & Urban $(n=954)$ & Rural (518) \\
\hline \multicolumn{4}{|l|}{ Sex, n (\%) } \\
\hline Male & $947(64.3)$ & $617(64.7)$ & $330(63.7)$ \\
\hline Female & $525(35.7)$ & $337(35.3)$ & $188(36.3)$ \\
\hline \multicolumn{4}{|l|}{ Patient age (months), $\mathrm{n}(\%)$} \\
\hline$<6$ & $461(31.0)$ & $282(29.5)$ & $179(34.5)$ \\
\hline $6-12$ & $494(34.0)$ & $342(35.9)$ & $152(29.2)$ \\
\hline $13-18$ & $228(15.5)$ & $138(14.5)$ & 89 (17.3) \\
\hline $19-24$ & $111(7.5)$ & $67(7.0)$ & $44(8.5)$ \\
\hline $25-30$ & $64(4.4)$ & $49(5.1)$ & $16(3.1)$ \\
\hline $31-36$ & $49(3.3)$ & $30(3.1)$ & $19(3.7)$ \\
\hline$>36$ & $65(4.4)$ & $46(4.8)$ & $19(3.7)$ \\
\hline Patient age in months, mean $( \pm S D)$ & $12.2(10.2)$ & $12.2(10.3)$ & $11.8(10.2)$ \\
\hline \multicolumn{4}{|l|}{ Length of stay in days } \\
\hline$<1$ & $28(1.9)$ & $14(1.5)$ & $14(2.7)$ \\
\hline $1-3$ & $233(15.8)$ & $65(6.9)$ & $168(32.4)$ \\
\hline $4-6$ & $792(53.7)$ & $481(50.3)$ & $311(60.1)$ \\
\hline $6+$ & $421(28.6)$ & $394(41.3)$ & $25(4.8)$ \\
\hline Length of stay, mean $( \pm S D)$ & $5.0(2.6)$ & $5.7(2.6)$ & $3.6(2.1)$ \\
\hline \multicolumn{4}{|l|}{ Mother's education, $\mathrm{n}(\%)$} \\
\hline No formal education & $207(14.0)$ & $146(15.3)$ & $60(11.6)$ \\
\hline Up to primary & $410(27.8)$ & $257(27.0)$ & $151(29.3)$ \\
\hline Secondary & $691(46.9)$ & $423(44.3)$ & $265(51.7)$ \\
\hline Higher & $166(11.3)$ & $128(13.4)$ & $38(7.4)$ \\
\hline \multicolumn{4}{|l|}{ Father's education, $\mathrm{n}(\%)$} \\
\hline No formal education & $251(17.0)$ & $165(17.3)$ & 85 (16.5) \\
\hline Up to primary & $428(29.0)$ & $249(26.1)$ & $178(34.5)$ \\
\hline Secondary & $567(38.5)$ & $360(37.8)$ & $203(39.7)$ \\
\hline Higher & $228(15.5)$ & $180(18.8)$ & $48(9.3)$ \\
\hline $\begin{array}{l}\text { Household size (members), mean } \\
( \pm S D)\end{array}$ & $5.2(2.2)$ & $4.9(1.6)$ & $5.9(2.3)$ \\
\hline \multicolumn{4}{|l|}{ Mother's occupation, n (\%) } \\
\hline Housewife & $1327(90.0)$ & $847(88.7)$ & $477(92.8)$ \\
\hline Informal worker & $36(2.4)$ & $29(3.0)$ & $7(1.3)$ \\
\hline Service & $58(3.9)$ & $40(4.1)$ & $18(3.5)$ \\
\hline Student & $13(0.8)$ & $4(0.4)$ & $9(1.7)$ \\
\hline Home worker & $20(1.4)$ & $18(2.0)$ & $1(0.2)$ \\
\hline Other & $18(1.2)$ & $16(1.7)$ & $2(0.4)$ \\
\hline \multicolumn{4}{|l|}{ Father's occupation, n (\%) } \\
\hline Farmer & $106(7.2)$ & $1(0.1)$ & $104(20.4)$ \\
\hline Informal worker & $151(10.2)$ & $116(12.1)$ & $35(6.8)$ \\
\hline Transport worker & $211(14.4)$ & $143(14.9)$ & $69(13.4)$ \\
\hline Salaried employee & $516(35.0)$ & $384(40.3)$ & $131(25.4)$ \\
\hline Business & $343(23.3)$ & $233(24.5)$ & $107(20.9)$ \\
\hline Other & $145(9.8)$ & $77(8.0)$ & 68 (13.2) \\
\hline $\begin{array}{l}\text { Average household monthly income } \\
\text { (US\$), mean }( \pm S D)\end{array}$ & $277.1(275.5)$ & $321.3(315.9)$ & $194.9(145.9)$ \\
\hline $\begin{array}{l}\text { Average household monthly } \\
\text { expenditure (US\$), mean ( } \pm \text { SD) }\end{array}$ & $213.3(151.6)$ & $249.5(165.7)$ & $146.2(87.8)$ \\
\hline $\begin{array}{l}\text { Household's average health } \\
\text { expenditure in the past } 3 \text { months } \\
\text { (US\$), mean }( \pm S D)\end{array}$ & $41.4(96.5)$ & $39.2(80.2)$ & $45.3(121.0)$ \\
\hline \multicolumn{4}{|l|}{ Wealth quintile, $n(\%)$} \\
\hline Poorest & $236(16.0)$ & $25(2.6)$ & $210(40.9)$ \\
\hline Poorer & $221(15.5)$ & $70(7.3)$ & $158(30.8)$ \\
\hline Middle & $263(17.8)$ & $151(15.9)$ & $110(21.3)$ \\
\hline Richer & $325(22.1)$ & $293(30.7)$ & $31(6.0)$ \\
\hline Richest & $421(28.6)$ & $415(43.5)$ & $5(1.0)$ \\
\hline
\end{tabular}

Resources used, distribution of average COI by type of facility and average household costs

Table 2 shows the resources used and the average costs by type of facility and the distribution of household costs per episode for each parameter. The most commonly used resources were medicines, admission fees, medical consumables and transportation. The mean household cost per episode was US $\$ 147$ (SD \pm 114.6 ) (median US\$116, IQR 95.3), comprising 35\% direct costs (US\$51) and 65\% (US\$96) indirect costs. The mean cost per episode was highest for households using private facilities (US\$268) and lowest for those using upazila health complex (US\$90). Overall, the mean cost was significantly higher among households that received treatment from urban health facilities (US\$177) compared with rural health facilities (US\$92) (online supplemental material 4 figure S1).

\section{Distribution of household cost per episode of severe} childhood pneumonia across income quintiles

Figure 1 shows the mean household COI per episode and its distribution across income quintiles. Overall, the costs were higher for higher income quintiles $(\mathrm{p}<0.001)$. The direct cost was US $\$ 24$ for the poorest households, while it was about three times higher for the richest households. Similarly, the indirect cost was also higher (US\$126) for the richest households.

We assessed COI as a percentage of household monthly income. OOP expenditure differed significantly across income groups and facility location $(p<0.001)$. Although the mean household cost per episode was higher for the richest quintiles, the poorest households spent more as a percentage of their monthly income compared with the richest households (urban: $43 \%$ vs $13 \%$; rural: $20 \%$ vs $5 \%$ ) (online supplemental material 5 figure $\mathrm{S} 2$ ).

\section{Households' coping strategies for managing costs}

Most households financed their child's treatment expenses from regular income (67\%), while $37 \%$ of the households required spending from their savings and 19\% reported borrowing to cover treatment costs. Regular income was the primary cost management strategy for both rural and urban residents $77 \%$ vs $62 \%$ ), while urban households borrowed more than rural households (23\% vs 10\%) (supplemental material 6 figure S3).

\section{Predictors of household costs per episode of childhood severe pneumonia}

Bivariate and multivariate logged linear regression models found that LoS, income quintile, type of healthcare facility and age of the child were significant predictors of household COI for childhood severe pneumonia. For instance, an additional day in the hospital was associated with a $13 \%$ increase in log-transformed total cost per household $(\mathrm{p}<0.001)$, and being in the richest income quintile was associated with a $24 \%$ increase relative to the poorest quintile $(\mathrm{p}<0.001)$. Children from urban areas had higher COI compared with children from rural areas $(33 \%$, $\mathrm{p}<0.001$ ) (table 3).

\section{Sensitivity analysis}

Household mean COI per episode was most sensitive to changes in average LoS and caregivers' income loss. A 1-day reduction in hospital LoS reduced household COI by $25 \%$, and a $20 \%$ increase in caregivers' time cost increased COI by $13 \%$ (figure 2).

\section{DISCUSSION}

In general, COI studies are used to define the economic burden of disease and to recommend policy for decision-making in order to efficiently allocate healthcare resources. The current study estimates household COI covering both direct and indirect costs at a highly detailed level. We also compared the distribution of costs across facility type and location, determined the 


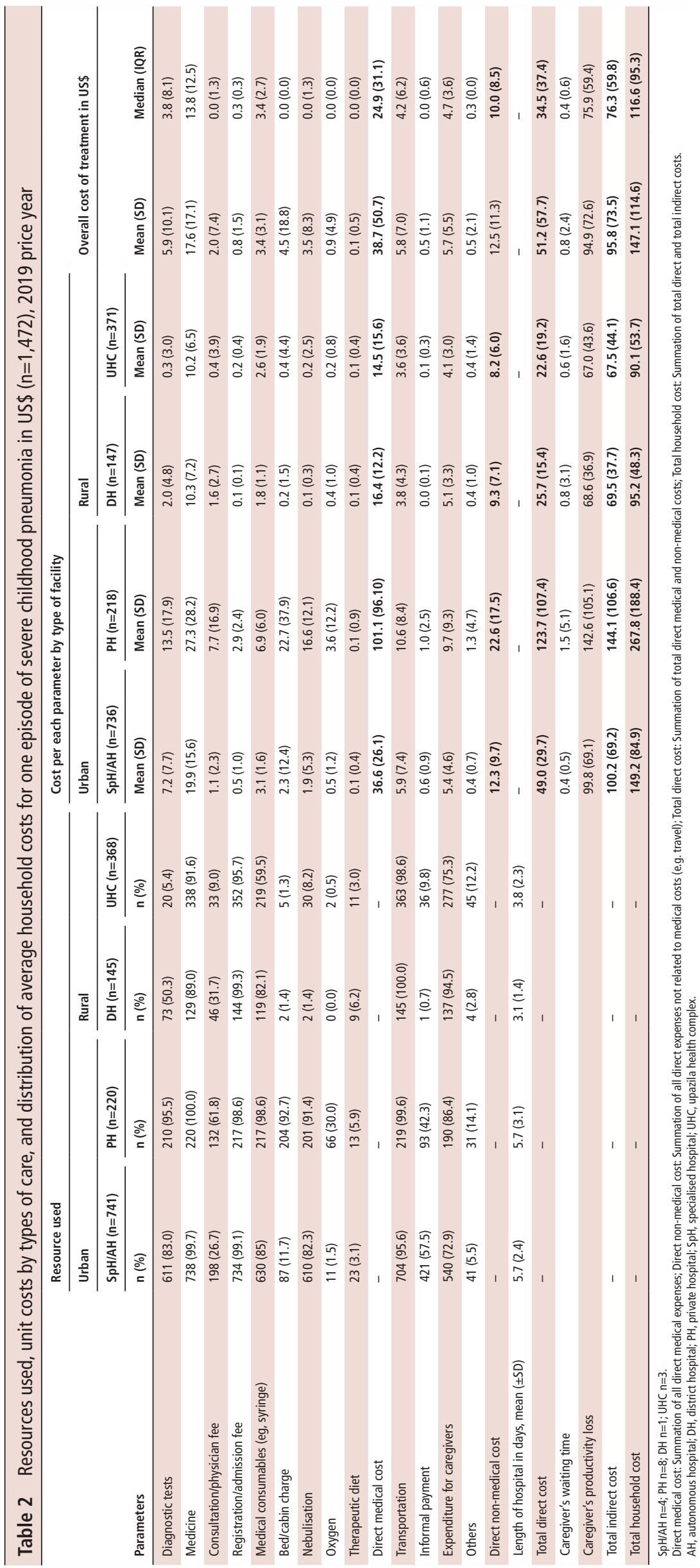




\section{Distribution of mean household costs per episode by income quintiles}

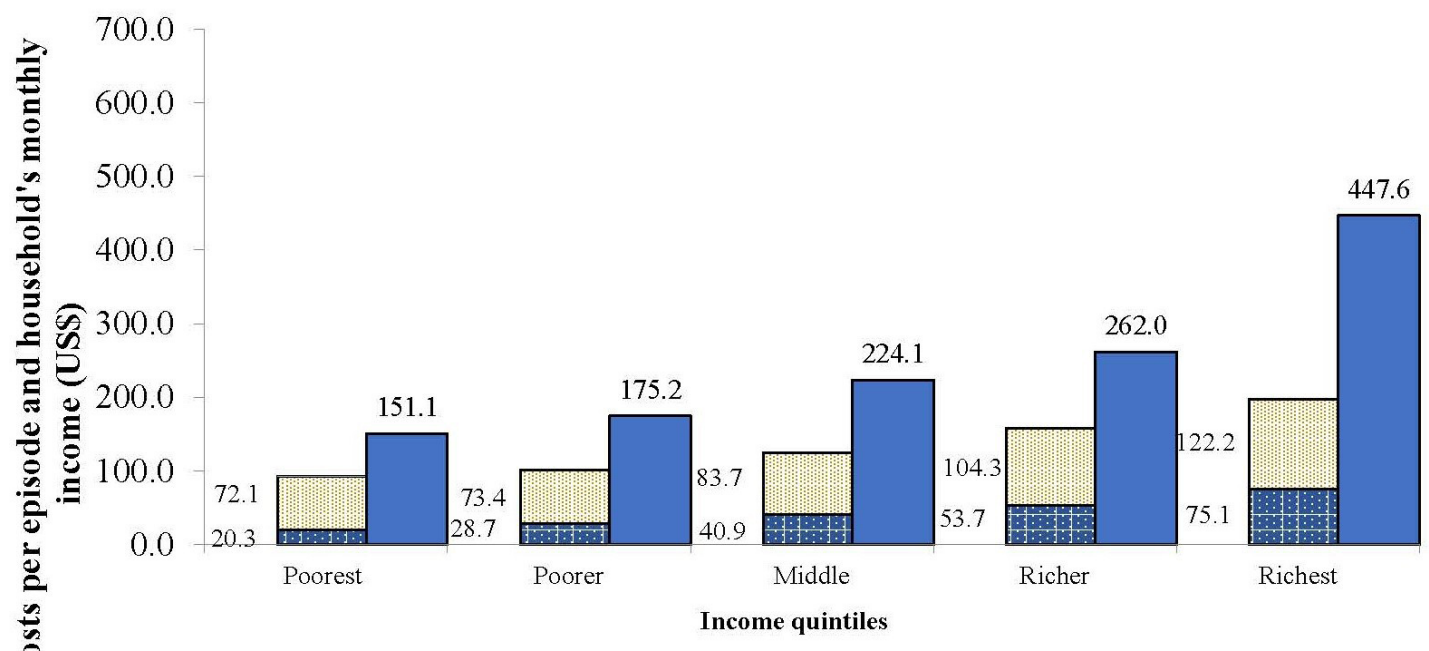

Indirect treatment cost per case (USS)

$\square$ Direct treatment cost per case (US\$)

$\square$ Household monthly income (US\$)

Figure 1 Distribution of mean household cost per episode of childhood severe pneumonia by wealth quintiles.

predictors of cost and performed a sensitivity analysis. Overall, our study provides a more detailed characterisation that indicates management of childhood severe pneumonia poses a substantial economic burden to households, particularly to the poorest socioeconomic groups and if treatment is provided by urban hospitals.

It is evident that household costs pose a substantial burden particularly to inpatient care. ${ }^{12}$ Findings from other LMICs reported household cost per patient ranged from US $\$ 21$ to US\$326 (2019 inflation-adjusted), although most studies reported only direct cost and therefore underestimated the total cost burden. ${ }^{18} 19$ 27-30 Our estimated per patient household costs are comparatively lower than the reported costs (2019 inflationadjusted) for other LMICs, such as Kenya (US\$260), ${ }^{31}$ India $\left(\right.$ US\$212) ${ }^{32}$ and Jordan (US\$616), ${ }^{33}$ but higher compared with Pakistan (US\$103). ${ }^{34}$ The cross-country cost variation may be explained by differences in the health system, in particular the contribution of OOP payment to health expenditure, as well as by methodological variation between studies in cost estimation, disease severity and type of facility providing care (community management, outpatient care and inpatient care). Our study also demonstrates that the cost of medicine constituted the major proportion of direct inpatient care costs. Consistent with our findings, several previous studies conducted in other LMICs also reported similar costs, in which the cost of medications was the major cost driver of the total OOP expense from households. ${ }^{2327} 3031$

High OOP expenditure can be largely attributed to the fact that there is a lack of public inpatient care facilities in Bangladesh, many with insufficient supply of required resources such as personnel, medicines and other medical consumables to treat children optimally. Health insurance would probably be the better solution to lower OOP cost, but these are limited in most LMICs including Bangladesh. ${ }^{20}{ }^{35}$ Earlier studies also reported unofficial or informal fees to gain access to public healthcare facilities, which increase the total cost of treatment. ${ }^{1930}$

Our findings demonstrate that OOP expenditure is a substantial burden particularly for poor socioeconomic groups, where health expenditure is comparatively lower in absolute terms compared with richer groups but higher in relative terms, as a proportion of monthly household income. OOP expenditure per episode was about one-third of the monthly household income of the poorest group, which would classify these households as facing catastrophic health expenditure (over $40 \%$ of the household income net of subsistence expenditure). ${ }^{36}$ OOP expenditure in this study was mainly sourced from regular income, followed by savings and borrowing. Likewise, other studies conducted in similar settings, including Bangladesh, revealed use of income, savings and borrowing with interest to manage treatment cost. ${ }^{2031}$

In Bangladesh, catastrophic healthcare expenditure pushes about six million people towards poverty. ${ }^{37}$ To mitigate this challenge, moving towards achieving universal health coverage, Bangladesh has health financing strategies to create health insurance schemes. For instance, a health insurance scheme for populations below the poverty line has been piloted in three subdistricts. ${ }^{37}$ Findings from this study underline the importance of effective and affordable health insurance for vulnerable families to protect children from pneumonia-specific mortality.

Our findings show that indirect costs are significantly higher than previously documented and constitute more than half of the mean household cost per episode. Detailed estimation of indirect costs has not previously been available for Bangladesh. An earlier study conducted in Germany reported 38\% indirect cost for pneumonia management. ${ }^{38}$ This difference might be due to the dissimilarity in healthcare systems in LMICs compared with those in high-income countries, since continuous caregiving is required from the family for inpatient services, particularly for children, in resource-poor settings. These findings reveal and emphasise the extent to which severe pneumonia interrupts household income and productivity. Consistent with our findings, several other studies conducted in LMIC settings including Bangladesh reported indirect costs as a major cost contributor for other infectious diseases, including cholera $(75 \%){ }^{16}$ malaria $(72 \%-94 \%)^{39} 40$ and visceral leishmaniasis $(53 \%){ }^{41}$ 
Table 3 Bivariate and multiple logged linear regression models ( $N=1472)$

\begin{tabular}{|c|c|c|c|c|}
\hline \multirow[b]{2}{*}{ Variables } & \multicolumn{2}{|l|}{ Unadjusted model } & \multicolumn{2}{|l|}{ Adjusted model } \\
\hline & Coefficient $(95 \% \mathrm{Cl})$ & $P$ value & Coefficient $(95 \% \mathrm{Cl})$ & $P$ value \\
\hline Length of stay & 0.15 (0.01 to 0.13 ) & $<0.001$ & $0.13(0.11$ to 0.15$)$ & $<0.001$ \\
\hline Patient age in months & $-0.01(-0.02$ to -0.01$)$ & $<0.001$ & $-0.1(-0.01$ to -0.01$)$ & $<0.01$ \\
\hline \multicolumn{5}{|l|}{ Mother's education } \\
\hline \multicolumn{5}{|l|}{ No formal education (ref) } \\
\hline Up to primary & $-0.21(-0.3$ to -0.1$)$ & $<0.001$ & $-0.01(-0.09$ to 0.07$)$ & 0.83 \\
\hline Secondary & $-0.11(-0.23$ to 0.00$)$ & 0.05 & $0.04(-0.03$ to 0.12$)$ & 0.27 \\
\hline Higher & $0.1(-0.05$ to 0.24$)$ & 0.19 & $0.09(-0.01$ to 0.19$)$ & 0.08 \\
\hline \multicolumn{5}{|l|}{ Father's education } \\
\hline \multicolumn{5}{|l|}{ No formal education (ref) } \\
\hline Up to primary & $-0.19(-0.3$ to -0.09$)$ & $<0.001$ & $-0.04(-0.1$ to 0.03$)$ & 0.3 \\
\hline Secondary & $-0.09(-0.19$ to 0.02$)$ & 0.1 & $-0.03(-0.1$ to 0.04$)$ & 0.41 \\
\hline Higher & $0.12(0.0$ to 0.24$)$ & 0.05 & $-0.01(-0.09$ to 0.07$)$ & 0.82 \\
\hline \multicolumn{5}{|l|}{ Wealth quintile } \\
\hline \multicolumn{5}{|l|}{ Poorest (ref) } \\
\hline Poorer & $0.13(0.04$ to 0.23$)$ & 0.01 & $0.02(-0.05$ to 0.09$)$ & 0.61 \\
\hline Middle & $0.32(0.22$ to 0.42$)$ & $<0.001$ & 0.09 (0.01 to 0.17$)$ & 0.02 \\
\hline Richer & 0.52 (0.43 to 0.62$)$ & $<0.001$ & 0.14 (0.05 to 0.23$)$ & $<0.001$ \\
\hline Richest & 0.73 (0.64 to 0.82 ) & $<0.001$ & 0.24 (0.014 to 0.34$)$ & $<0.001$ \\
\hline \multicolumn{5}{|l|}{ Place of residence } \\
\hline Urban & 0.61 (0.55 to 0.66$)$ & $<0.001$ & - & - \\
\hline \multicolumn{5}{|l|}{ Rural (ref) } \\
\hline \multicolumn{5}{|l|}{ Father's occupation } \\
\hline \multicolumn{5}{|l|}{ Transport worker (ref) } \\
\hline Informal worker & $0.27(0.15$ to 0.40$)$ & $<0.001$ & $-0.09(-0.18$ to 0.00$)$ & 0.06 \\
\hline Farmer & $0.32(0.2$ to 0.44$)$ & $<0.001$ & $-0.11(-0.2$ to -0.02$)$ & 0.02 \\
\hline Salaried employee & $0.43(0.33$ to 0.53$)$ & $<0.001$ & $-0.06(-0.14$ to 0.02$)$ & 0.16 \\
\hline Business & $0.43(0.32$ to 0.53$)$ & $<0.001$ & $0.0(-0.09$ to 0.09$)$ & 0.98 \\
\hline Others & $0.36(0.21$ to 0.50$)$ & $<0.001$ & $-0.08(-0.18$ to 0.02$)$ & 0.12 \\
\hline \multicolumn{5}{|l|}{ Type of facility } \\
\hline Autonomous/specialised hospital & $0.5(0.44$ to 0.56$)$ & $<0.001$ & $0.14(0.06$ to 0.22$)$ & $<0.001$ \\
\hline Private hospital & 1.06 (0.97 to 0.14$)$ & $<0.001$ & $0.68(0.59$ to 0.76$)$ & $<0.001$ \\
\hline District hospital & $0.08(-0.01$ to 0.17$)$ & 0.07 & 0.17 (0.11 to 0.24$)$ & $<0.001$ \\
\hline \multicolumn{5}{|l|}{ Upazila health complex (ref) } \\
\hline Constant & - & - & 3.93 (3.78 to 4.08$)$ & $<0.001$ \\
\hline $\mathrm{N}$ & 1472 & & & \\
\hline Probability $>F$ & $<0.001$ & & & \\
\hline R-squared & 0.63 & & & \\
\hline Root MSE & 0.37 & & & \\
\hline Mean VIF & 2.67 & & & \\
\hline
\end{tabular}

MSE, mean square error; ref, reference; VIF, variance inflation factor.

Costs varied between urban and rural areas, with household COI significantly greater when care was sought from urbanlocated hospitals. An earlier study reported higher treatment costs if care was sought from tertiary level hospitals compared with secondary level, and this finding was reaffirmed in Zhang et al's review. ${ }^{12} 27$ This difference in costs might be due to the relative availability of secondary level public healthcare facilities in rural areas, which provide highly subsidised healthcare for pneumonia treatment-related costs, while tertiary hospitals have expensive resources. ${ }^{27} 31$

Findings reveal that households face a substantial economic burden to manage treatment cost. Although Bangladesh has introduced Haemophilus influenzae type b (Hib) in 2009 and 10 -valent pneumococcal conjugate vaccine $(\mathrm{PCV}-10)$ vaccine in 2015 to prevent vaccine-preventable pneumonia, this study reveals the continuing considerable economic burden of child pneumonia despite successful (84\%) immunisation coverage. ${ }^{42}$ Further research is needed to assess the contribution of vaccinepreventable pneumonia to the health and economic burden in Bangladesh. In the multivariate analysis, LoS, income quintile, type of facility and age of the child are identified as important predictors of household cost for severe childhood pneumonia management. Household costs in our study were most sensitive to hospital LoS. The average LoS was about 5 days, which is similar to the LoS described in studies conducted in lowresource settings such as Bangladesh, Kenya, Zambia, Jordan and Colombia. ${ }^{31} 323543$ The negative association between age and COI may well reflect disease severity, with relatively more severe disease due to the immature immune status of young children $<2$ years old. ${ }^{14}$ With respect to the impact of income quintile, it is well reported that the wealthiest households consumed more healthcare services than the poorest counterparts in Bangladesh. ${ }^{14} 154144$ The higher COI for wealthier households is likely to reflect affordability in contexts like Bangladesh, where households need to pay OOP fees for most healthcare services. In addition, the skew in our sample towards the upper income quintiles suggests that a large proportion of households in the lower income quintile do not seek care, likely due to economic burden. Strong policy initiatives are therefore essential to ensure the affordability and accessibility of healthcare services for 


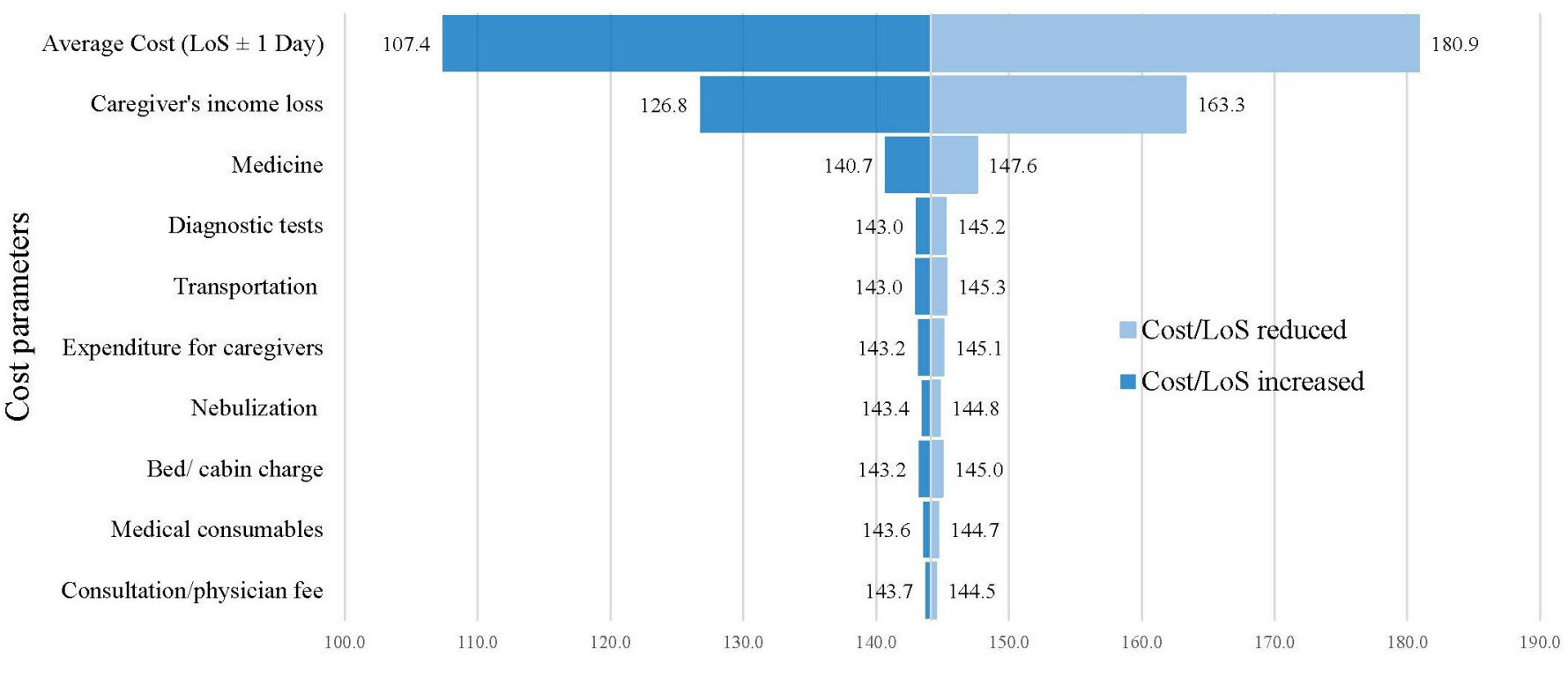

\section{Mean household cost variation by each parameter}

Figure 2 Tornado diagram of one-way sensitivity analysis using important cost parameters. Each bar represents the influence of variation on each parameter in relation to the base case results through the vertical line in the middle, with the most cost-sensitive parameters arranged from top to bottom. LoS, length of stay.

childhood pneumonia, particularly for poorer groups, to reduce inequality.

\section{Strengths and limitations}

This study presents detailed household COI estimation including indirect costs and cost variation among socioeconomic groups and households' coping strategies and determined the predictors of cost using primary data with a large sample size. Despite these strengths, this study has several limitations. First, indirect costs to households for severe pneumonia management might be underestimated because we valued unpaid time with the minimum wage rate. Second, since cost data were collected retrospectively, the study is subject to some recall bias because the interviewees needed to recall expenses. However, to reduce recall bias, they were asked to review prescriptions and receipts to complete the questionnaire. Finally, given the study perspective, we did not incorporate any costs borne by the provider, which might contribute to the underestimation of the total economic cost.

\section{CONCLUSIONS}

Severe pneumonia in young children is associated with substantial economic burden for households in Bangladesh. Costs varied significantly across facility type and location. In addition to ensuring Hib and PCV vaccine coverage, the findings highlight the potential efficiency and equity concerns to improve accessibility and affordability, particularly for poorer socioeconomic groups, to reduce household economic burden.

\section{Twitter Marufa Sultana @marufa_sultana}

Acknowledgements The International Centre for Diarrhoeal Disease Research, Bangladesh is grateful to the governments of Bangladesh, Canada, Sweden and the UK for providing core/unrestricted support. icddr,b acknowledges with gratitude the commitment of UBS Optimus Foundation and UNICEF Switzerland for funding the trial.

Contributors MS and LG conceptualised and designed the study. MS, NHA, ASGF, GJF, NG, MJC and TA designed the study, data collection instruments, supervised the data collection and drafted the initial manuscript. MS and NA supervised the data collection and analysed the data. LG supervised each stage of drafting the initial manuscript. NHA, NA, ASGF, GJF, NG, MJC, TA and LG critically reviewed and revised the manuscript. All authors approved the final manuscript as submitted and agree to be accountable for all aspects of the work.

Funding This work was jointly supported by UNICEF and UBS Optimus Foundation, Switzerland.

Competing interests None declared.

Patient consent for publication Not required.

Ethics approval The clinical trial protocol (trial registration NCT02669654) has been approved by the ethical review committee of icddr,b (PR-14066). The economic evaluation protocol has been approved by Deakin University Human Research Ethics Committee (DUHREC) (2018-149).

Provenance and peer review Not commissioned; externally peer reviewed. Supplemental material This content has been supplied by the author(s). It has not been vetted by BMJ Publishing Group Limited (BMJ) and may not have been peer-reviewed. Any opinions or recommendations discussed are solely those of the author(s) and are not endorsed by BMJ. BMJ disclaims all liability and responsibility arising from any reliance placed on the content. Where the content includes any translated material, BMJ does not warrant the accuracy and reliability of the translations (including but not limited to local regulations, clinical guidelines, terminology, drug names and drug dosages), and is not responsible for any error and/or omissions arising from translation and adaptation or otherwise.

Open access This is an open access article distributed in accordance with the Creative Commons Attribution Non Commercial (CC BY-NC 4.0) license, which permits others to distribute, remix, adapt, build upon this work non-commercially, and license their derivative works on different terms, provided the original work is properly cited, appropriate credit is given, any changes made indicated, and the use is non-commercial. See: http://creativecommons.org/licenses/by-nc/4.0/.

\section{ORCID iDs}

Marufa Sultana http://orcid.org/0000-0003-2475-6497

Tahmeed Ahmed http://orcid.org/0000-0002-4607-7439

\section{REFERENCES}

1 UNICEF. One is too many: ending child deaths from pneumonia and diarrhoea. New York, NY 10017, USA, 2016. https://data.unicef.org/wp-content/uploads/2017/11/ UNICEF-Pneumonia-Diarrhoea-report2016-web-version_final.pdf\%0A\%0A

2 Liu L, Oza S, Hogan D, et al. Global, regional, and national causes of under-5 mortality in 2000-15: an updated systematic analysis with implications for the sustainable development goals. Lancet 2016;17:3027-35. 
3 International Vaccine Access Center (IVAC). Pneumonia \& Diarrhea Progress Report 2015: Sustainable Progress in the Post-2015 Era. USA: Johns Hopkins Bloomberg School of Public Health, 2015: 1-42. http://www.jhsph.edu/research/centers-andinstitutes/ivac/resources/IVAC-2015-Pneumonia-Diarrhea-Progress-Report.pdf

4 McAllister DA, Liu L, Shi T, et al. Global, regional, and national estimates of pneumonia morbidity and mortality in children younger than 5 years between 2000 and 2015: a systematic analysis. Lancet Glob Health 2019;7:e47-57.

5 Rudan I, Boschi-Pinto C, Biloglav Z, et al. Epidemiology and etiology of childhood pneumonia. Bull World Health Organ 2008;86:408-16.

6 Walker CLF, Rudan I, Liu L, et al. Global burden of childhood pneumonia and diarrhoea. Lancet 2013;381:1405-16.

7 Chisti MJ, Salam MA, Smith JH, et al. Bubble continuous positive airway pressure for children with severe pneumonia and hypoxaemia in Bangladesh: an open, randomised controlled trial. Lancet 2015;386:1057-65.

8 World Health Organization. Pocket Book of Hospital Care for Children - Guidelines for the Management of Common Child-hood Illnesses. 2nd edition. Geneva, 2013.

9 Lozano R, Naghavi M, Foreman K, et al. Global and regional mortality from 235 causes of death for 20 age groups in 1990 and 2010: a systematic analysis for the global burden of disease study 2010. Lancet 2012;380:2095-128.

10 UNICEF. Pneumonia. Available: http://data.unicef.org/child-health/pneumonia.html\# sthash.rLMWAkoB.dpuf [Accessed 2 Mar 2020].

11 National Institute of Population Research and Training (NIPORT), Mitra and Associates, and ICF Inter- national. Bangladesh Demographic and Health Survey 2014: Key Indicators. Dhaka, Bangladesh, and Rockville, Maryland, USA: NIPORT, Mitra and Associates, and ICF International, 2015

12 Zhang S, Sammon PM, King I, et al. Cost of management of severe pneumonia in young children: systematic analysis. J Glob Health 2016;6:010408.

13 Usuf E, Mackenzie G, Sambou S, et al. The economic burden of childhood pneumococcal diseases in the Gambia. Cost Eff Resour Alloc 2016;14:4.

14 Sultana M, Sarker AR, Sheikh N, et al. Prevalence, determinants and health careseeking behavior of childhood acute respiratory tract infections in Bangladesh. PLOS One 2019;14:e0210433.

15 Sarker AR, Sultana M, Mahumud RA, et al. Economic costs of hospitalized diarrheal disease in Bangladesh: a societal perspective. Glob Health Res Policy 2018;3:1.

16 Sarker AR, Islam Z, Khan IA, et al. Cost of illness for cholera in a high risk urban area in Bangladesh: an analysis from household perspective. BMC Infect Dis 2013;13:518.

17 Tahsina T, Ali NB, Siddique MAB, et al. Determinants of hardship financing in coping with out of pocket payment for care seeking of under five children in selected rural areas of Bangladesh. PLoS One 2018;13:e0196237.

18 Halder AK, Luby SP, Akhter S, et al. Incidences and Costs of IIness for Diarrhea and Acute Respiratory Infections for Children $<5$ Years of Age in Rural Bangladesh. Am J Trop Med Hyg 2017;96:953-60.

19 Ashraf H, Mahmud R, Alam NH, et al. Randomized controlled trial of day care versus hospital care of severe pneumonia in Bangladesh. Pediatrics 2010;126:e807-15.

20 Alamgir NI, Naheed A, Luby SP. Coping strategies for financial burdens in families with childhood pneumonia in Bangladesh. BMC Public Health 2010;10:622.

21 Drummond MF, Sculpher MJ, Claxton K. Methods for the economic evaluation of health care programmes. 4th edn. Newyork: Oxford University Press, 2015.

22 Xie F, Thumboo J, Fong K-Y, et al. A study on indirect and intangible costs for patients with knee osteoarthritis in Singapore. Value Health 2008;11:S84-90.

23 Memirie ST, Metaferia ZS, Norheim OF, et al. Household expenditures on pneumonia and diarrhoea treatment in Ethiopia: a facility-based study. BMJ Glob Health 2017;2:e000166.

24 Javanbakht M, Baradaran HR, Mashayekhi A, et al. Cost-Of-Illness analysis of type 2 diabetes mellitus in Iran. PLoS One 2011;6:e26864.
25 Gao L, Xia L, Pan S-Q, et al. Burden of epilepsy: a prevalence-based cost of illness study of direct, indirect and intangible costs for epilepsy. Epilepsy Res 2015;110:146-56.

26 Briggs A, Clark T, Wolstenholme J, et al. Missing. presumed at random: cost-analysis of incomplete data. Health Econ 2003;12:377-92.

27 Madsen HO, Hanehøj M, Das AR, et al. Costing of severe pneumonia in hospitalized infants and children aged 2-36 months, at a secondary and tertiary level hospital of a not-for-profit organization. Trop Med Int Health 2009;14:1315-22.

28 Hussain $\mathrm{H}$, Waters $\mathrm{H}$, Khan AJ, et al. Economic analysis of childhood pneumonia in northern Pakistan. Health Policy Plan 2008:23:438-42.

29 Ashraf H, Alam NH, Sultana M, et al. Day clinic vs. hospital care of pneumonia and severe malnutrition in children under five: a randomised trial. Trop Med Int Health 2019;24:922-31.

30 Anh DD, Riewpaiboon A, Tho LH, et al. Treatment costs of pneumonia, meningitis, sepsis, and other diseases among hospitalized children in Viet Nam. J Health Popul Nutr 2010;28:436-42.

31 Ayieko P, Akumu AO, Griffiths UK, et al. The economic burden of inpatient paediatric care in Kenya: household and provider costs for treatment of pneumonia, malaria and meningitis. Cost Eff Resour Alloc 2009:7:3.

32 Khuri-Bulos N, Williams JV, Shehabi AA, et al. Burden of respiratory syncytial virus in hospitalized infants and young children in Amman, Jordan. Scand I Infect Dis 2010;42:368-74.

33 Saha L, Kaur S, Khosla P. Pharmacoeconomic analysis of drugs used in the treatment of pneumonia in paediatric population in a tertiary care hospital in India-A cost-ofillness study. Medical sciences 2017:5:33.

34 Hussain $\mathrm{H}$, Waters $\mathrm{H}$, Omer SB, et al. The cost of treatment for child pneumonias and meningitis in the Northern areas of Pakistan. Int I Health Plann Manage 2006:21:229-38.

35 Chola L, Robberstad B. Estimating average inpatient and outpatient costs and childhood pneumonia and diarrhoea treatment costs in an urban health centre in Zambia. Cost Eff Resour Alloc 2009;7:16.

36 World Health Organization. Distribution of health payments and catastrophic expenditures methodology / by Ke Xu. World Health organization, 2005. Available: https://apps.who.int/iris/handle/10665/69030

37 Joarder T, Chaudhury TZ, Mannan I. Universal health coverage in Bangladesh: activities, challenges, and suggestions. Psyche 2019;2019:4954095.

38 Ehlken B, Ihorst G, Lippert B, et al. Economic impact of community-acquired and nosocomial lower respiratory tract infections in young children in Germany. Eur J Pediatr 2005; 164:607-15.

39 Deressa W, Hailemariam D, Ali A. Economic costs of epidemic malaria to households in rural Ethiopia. Trop Med Int Health 2007;12:1148-56

40 Attanayake N, Fox-Rushby J, Mills A. Household costs of 'malaria' morbidity: a study in Matale district, Sri Lanka. Trop Med Int Health 2000;5:595-606.

41 Uranw S, Meheus F, Baltussen R, et al. The household costs of visceral leishmaniasis care in south-eastern Nepal. PLoS Negl Trop Dis 2013;7:e2062.

42 Sarker AR, Akram R, Ali N, et al. Coverage and factors associated with full immunisation among children aged 12-59 months in Bangladesh: insights from the nationwide cross-sectional demographic and health survey. BMJ Open 2019;9:e028020.

43 Alvis-Guzman N, Orozco-Africano J, Paternina-Caicedo A, et al. Treatment costs of diarrheal disease and all-cause pneumonia among children under-5 years of age in Colombia. Vaccine 2013;31:C58-62.

44 Mahumud RA, Sarker AR, Sultana M, et al. Distribution and determinants of out-of-pocket healthcare expenditures in Bangladesh. J Prev Med Public Health 2017:50:91-9 